\title{
REVIEW
}

Open Access

\section{Genetic testing in inherited endocrine disorders: joint position paper of the European reference network on rare endocrine conditions (Endo-ERN)}

Thomas Eggermann ${ }^{1 *}$ D, Miriam Elbracht ${ }^{1}$, Ingo Kurth ${ }^{1}$, Anders Juul ${ }^{2,3}$, Trine Holm Johannsen ${ }^{2,3}$, Irène Netchine ${ }^{4}$, George Mastorakos ${ }^{5}$, Gudmundur Johannsson ${ }^{6}$, Thomas J. Musholt ${ }^{7}$, Martin Zenker ${ }^{8}$, Dirk Prawitt ${ }^{9}$, Alberto M. Pereira ${ }^{10}$, Olaf Hiort ${ }^{11}$ and on behalf of the European Reference Network on Rare Endocrine Conditions (ENDO-ERN

\begin{abstract}
Background: With the development of molecular high-throughput assays (i.e. next generation sequencing), the knowledge on the contribution of genetic and epigenetic alterations to the etiology of inherited endocrine disorders has massively expanded. However, the rapid implementation of these new molecular tools in the diagnostic settings makes the interpretation of diagnostic data increasingly complex.

Main body: This joint paper of the ENDO-ERN members aims to overview chances, challenges, limitations and relevance of comprehensive genetic diagnostic testing in rare endocrine conditions in order to achieve an early molecular diagnosis. This early diagnosis of a genetically based endocrine disorder contributes to a precise management and helps the patients and their families in their self-determined planning of life. Furthermore, the identification of a causative (epi)genetic alteration allows an accurate prognosis of recurrence risks for family planning as the basis of genetic counselling. Asymptomatic carriers of pathogenic variants can be identified, and prenatal testing might be offered, where appropriate.
\end{abstract}

Conclusions: The decision on genetic testing in the diagnostic workup of endocrine disorders should be based on their appropriateness to reliably detect the disease-causing and -modifying mutation, their informational value, and cost-effectiveness. The future assessment of data from different omic approaches should be embedded in interdisciplinary discussions using all available clinical and molecular data.

Keywords: Rare endocrine conditions, Genetic testing, Imprinting disorders, Short stature - glucose and insulin homeostasis - Hypogonadotropic hypogonadism - differences/disorders of sex development

\footnotetext{
* Correspondence: teggermann@ukaachen.de

'Institute of Human Genetics, Medical Faculty, RWTH Aachen, Pauwelsstr. 30, 52074 Aachen, Germany

Full list of author information is available at the end of the article
}

C C The Author(s). 2020 Open Access This article is licensed under a Creative Commons Attribution 4.0 International License, which permits use, sharing, adaptation, distribution and reproduction in any medium or format, as long as you give appropriate credit to the original author(s) and the source, provide a link to the Creative Commons licence, and indicate if changes were made. The images or other third party material in this article are included in the article's Creative Commons licence, unless indicated otherwise in a credit line to the material. If material is not included in the article's Creative Commons licence and your intended use is not permitted by statutory regulation or exceeds the permitted use, you will need to obtain permission directly from the copyright holder. To view a copy of this licence, visit http://creativecommons.org/licenses/by/4.0/. The Creative Commons Public Domain Dedication waiver (http://creativecommons.org/publicdomain/zero/1.0/) applies to the data made available in this article, unless otherwise stated in a credit line to the data. 


\section{Background}

Genetic disorders compose a substantial fraction of human diseases, and it is estimated that nearly $5 \%$ of live births have a genetically driven illness recognizable until the 25th year of life [1]. However, it is a challenge to diagnose these rare conditions by assessing clinical features and conventional diagnostic testing alone. As a result, many patients and their families undergo a longlasting diagnostic odyssey.

In clinical endocrine practice, genetic testing is primarily requested to confirm a suspected clinical and endocrine diagnosis, in particular in case the clinical features are ambiguous. Additionally, it also contributes to the identification of presymptomatic individuals. Thereby, their risk to develop an inherited endocrine disorder can be predicted, and prophylactic measures might be taken (i.e. thyroidectomy in carriers of specific MEN2 variants). This risk can also be determined in relatives of mutation carriers, and the knowledge on an inherited genetic variant is the basis to advice the patients' family in respect of family planning and prenatal testing. Finally, the precise determination of the molecular alteration causing the endocrine disorder allows to understand its pathophysiology and thereby to develop and apply an adapted therapy.

In recent years, high throughput genetic tests (i.e. next generation sequencing (NGS)) have become increasingly available for clinical use at reasonable costs, and significant progress has been achieved regarding the detection rate in human genetic diagnostic testing $[2,3]$. As a result, a diagnostic yield of up to $40 \%$ can currently been achieved in genetic heterogeneous disorders, depending on the precision of the clinical assessment and the disorder itself (e.g. [4], for general review: [5]). Molecular alterations also play a major role in tumor development, and NGS has turned out to be an appropriate tool (for review: [6]) for tumor profiling as the basis for treatment and prognosis. Accordingly, genetic testing has become an indispensable component of the comprehensive diagnostic workup in pediatric endocrinology, and increasingly also as part of adult endocrine diagnostics (Table 1), in addition to the common biochemical laboratory analysis. Consequently, the demand for genetic testing continues to increase, and the physician asking for genetic analysis should be aware of the indications for testing, of the used methods and their chances of success, but also of their limitations.

This position paper of the European reference networks on rare endocrine conditions (ENDO-ERN; www. https://endo-ern.eu) summarizes the current role of genetic testing in the diagnostic workup of (inherited) endocrine disorders and emphasizes the chances and advantages of modern genetic tests as well as the accompanying challenges and limitations. The paper will mainly refer to molecular germline variants and congenital disorders and will not cover genetic testing of somatic variants in tumors, which requires different considerations.

Due to the permanent improvement in diagnostic testing and increasing number of genetic factors associated with endocrine disorders, this review can only provide an overview on testing strategies and available tests. The authors therefore kindly ask the readers to visit curated and public databases like orphanet (https://www.orpha. net/consor/cgi-bin/Disease_Search.php?lng=EN) to get an up-dated overview on available diagnostic tests and therapies.

\section{Relevance of genetic testing for the management of endocrine disorders}

The decision on the application of genetic tests is not only based on considerations about the benefit for the patient and therapeutic options which can be inferred from the genetic test result, but should also be based on the feasibility of genetic tests, their availability, informational value, and cost-effectiveness. It should be mentioned that predictive genetic testing in children without therapeutic consequences is not indicated and even violates the law in some countries.

The prerequisite of a targeted and efficient genetic test is the comprehensive evaluation of phenotype (deep phenotyping) and recording of the medical history by using a standardized and curated terminology (e.g. Human Phenotype Ontology (HPO)), which helps to specify the order for genetic testing (Fig. 1). In many instances, specialized endocrine diagnostic approaches with baseline and dynamic tests are required and may be supplemented by dedicated functional imaging procedures and specific hormonal analyses. Furthermore, precise molecular diagnosis may direct laboratory evaluation to "condition-specific target ranges" rather than to comparison to usual reference ranges [8] (Table 1).

An example for the need of precise clinical data as the basis for targeted genetic testing is short stature [9] where the first assessment comprises the analysis of growth parameters like height, weight and head circumference, as well as growth velocity and the skeletal features (bone deformities, demineralization, etc.). Endocrine tests (e.g. serum IGF1 concentration) may point towards the basic endocrinopathy and narrow down the specific defect, such as IGF1 deficiency or IGF1 resistance. Another example is the determination of AntiMüllerian hormone (AMH) concentration in serum of patients suspected of Persistent Müllerian Duct Syndrome (PMDS), which identifies relevant genes to be sequenced: If serum $\mathrm{AMH}$ is undetectable the $A M H$ gene should be sequenced, whereas analysis of the $A M H-R$ gene is indicated in case AMH is normal/high in PMDS. 
Eggermann et al. Orphaned Journal of Rare Diseases

(2020) 15:144

Page 3 of 16

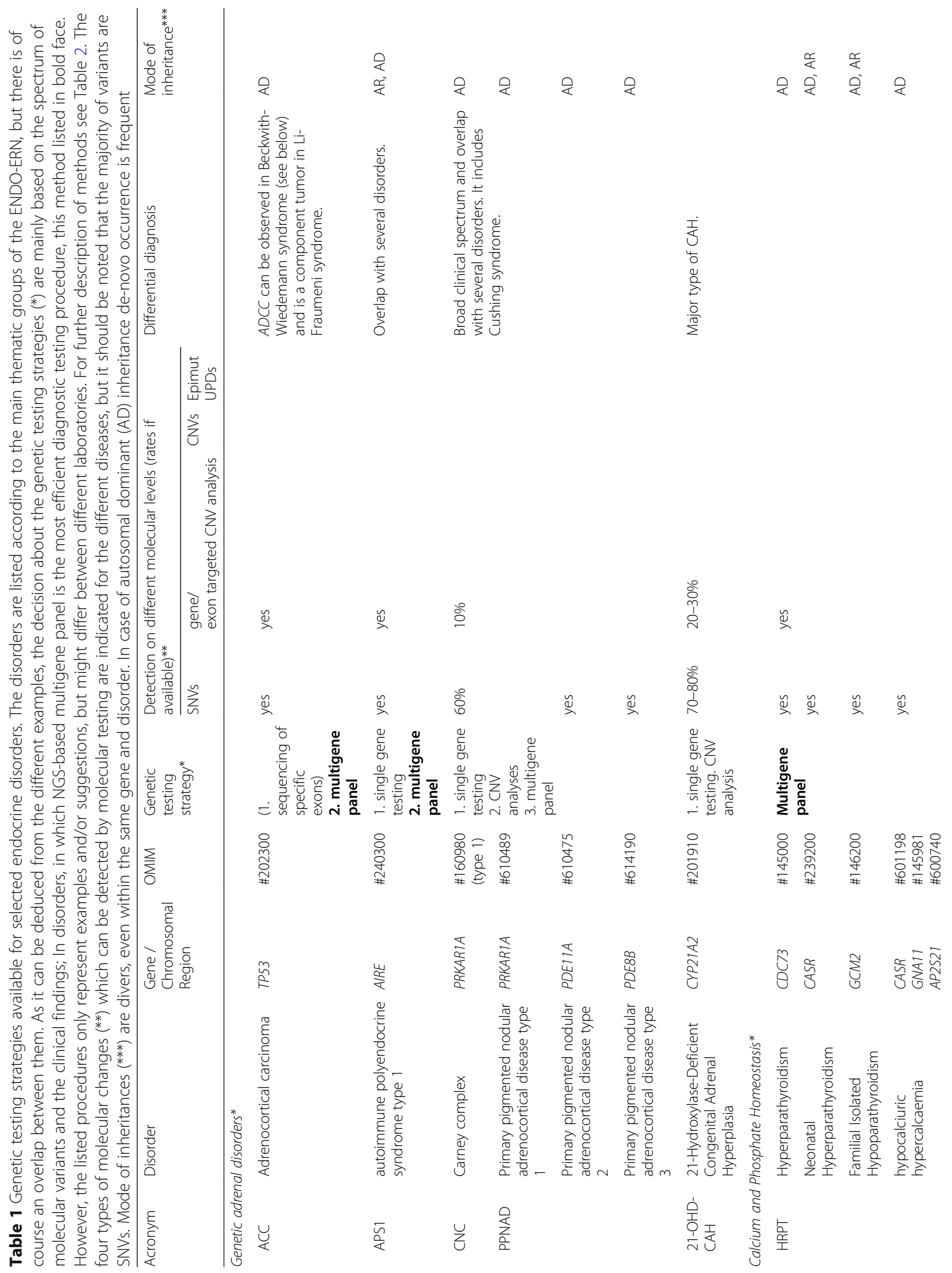




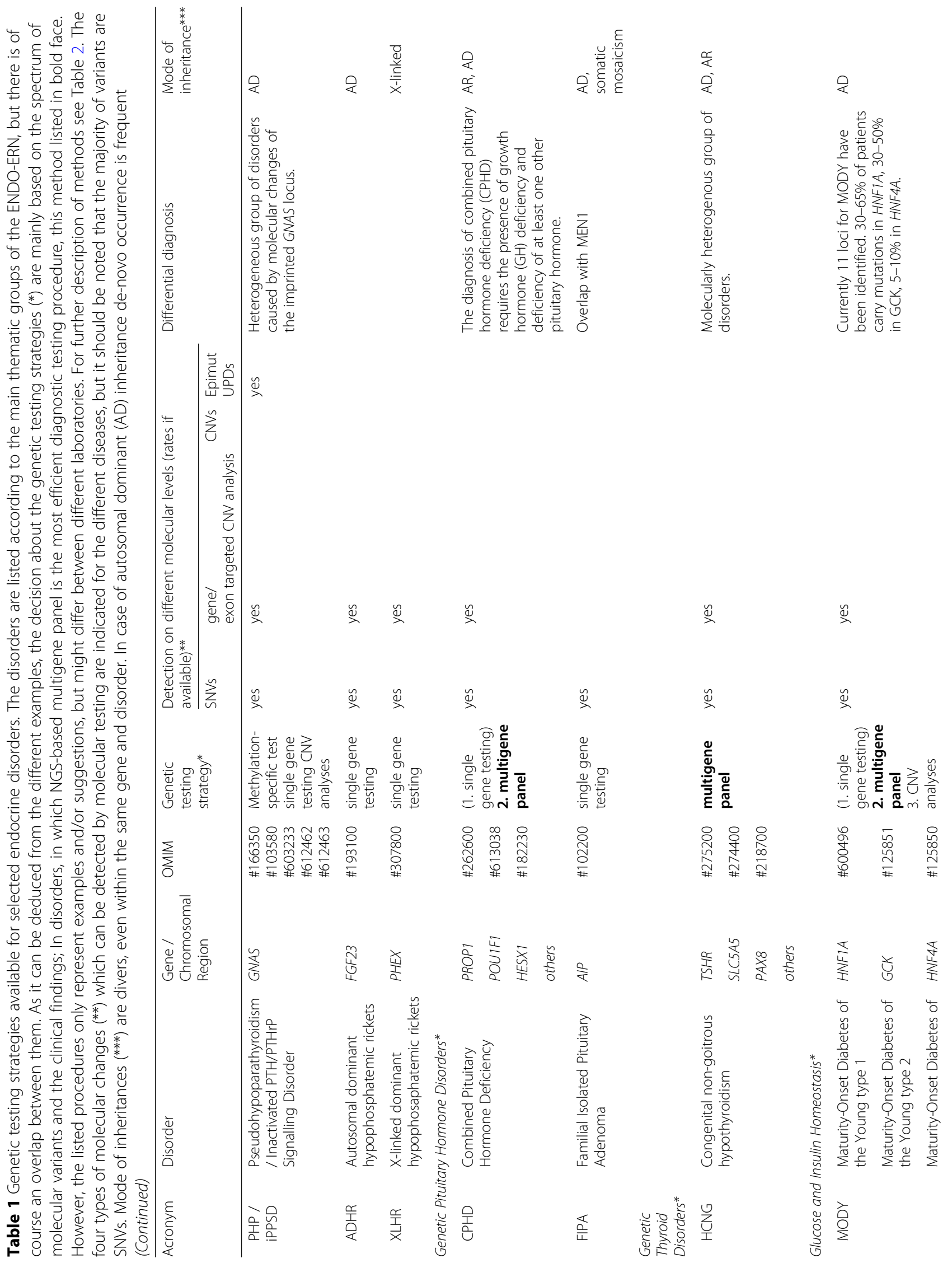




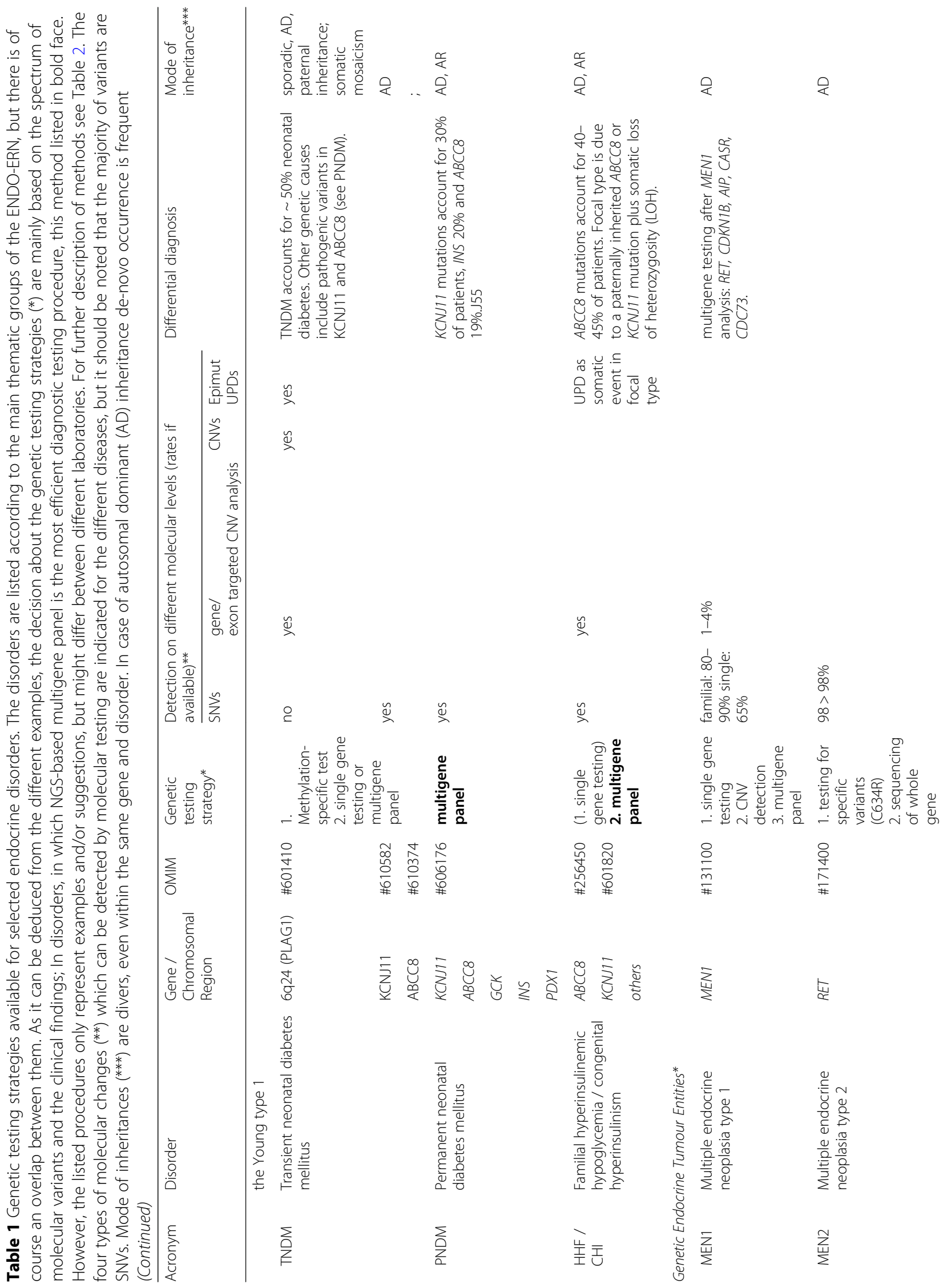




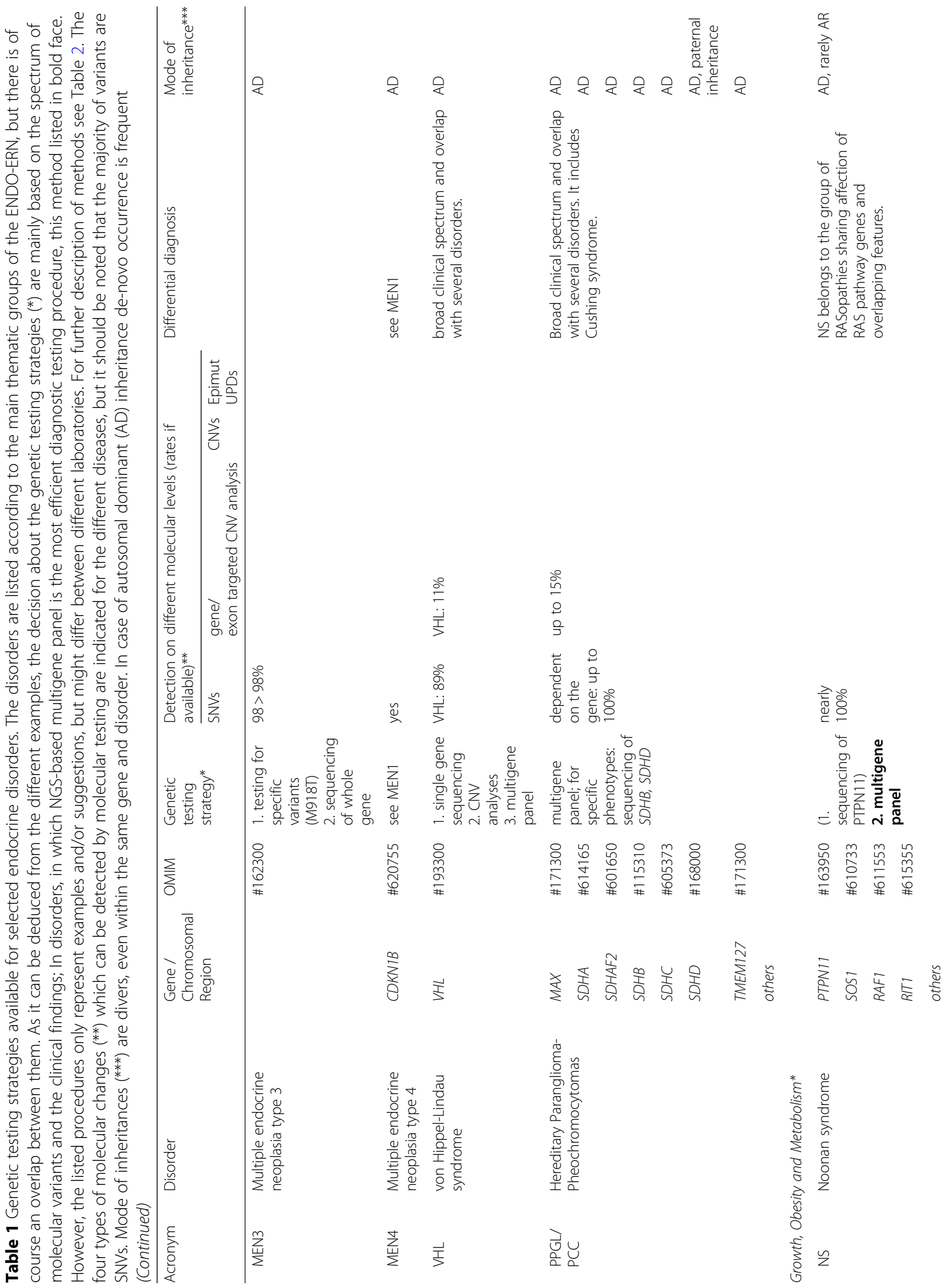




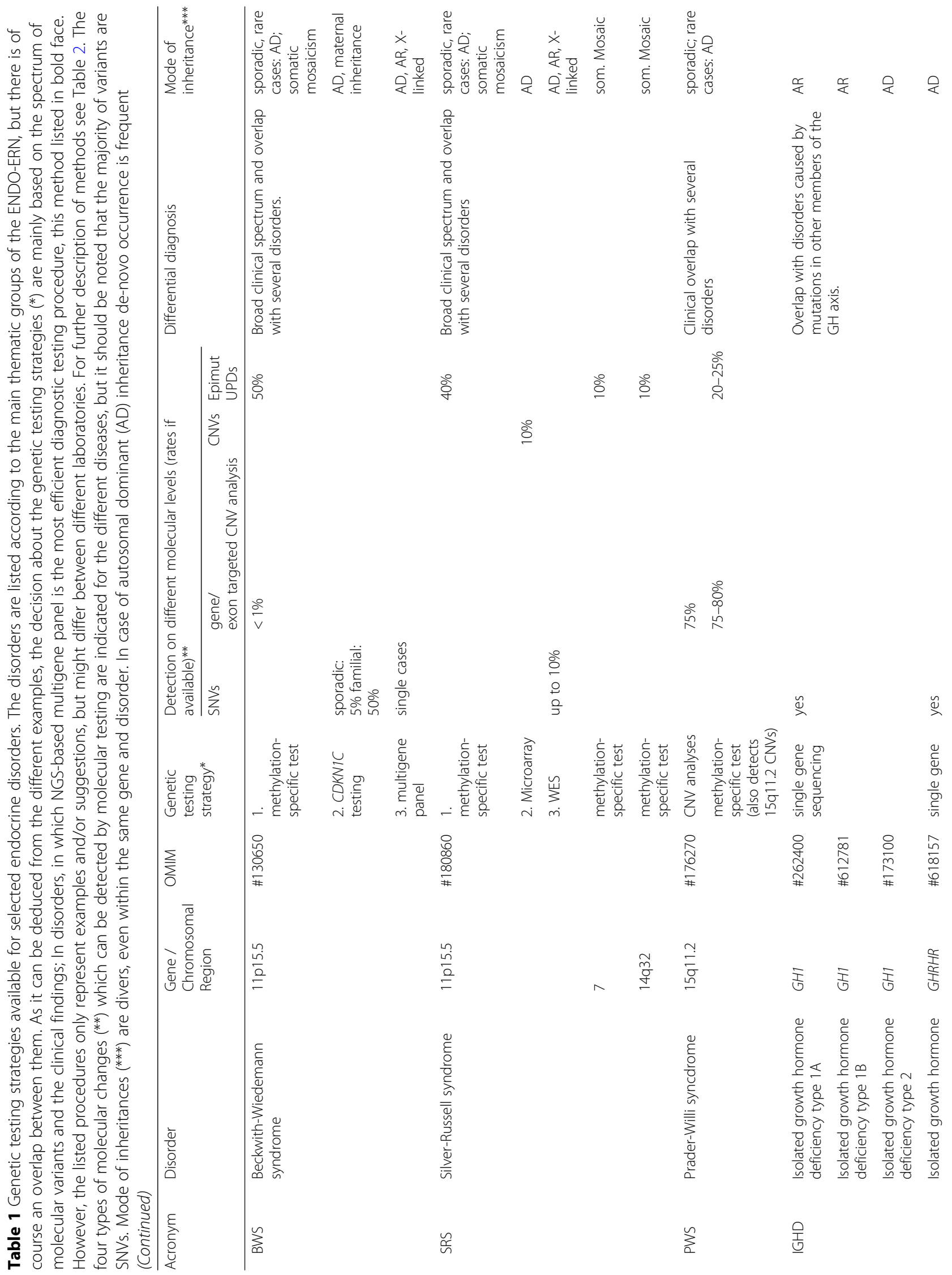




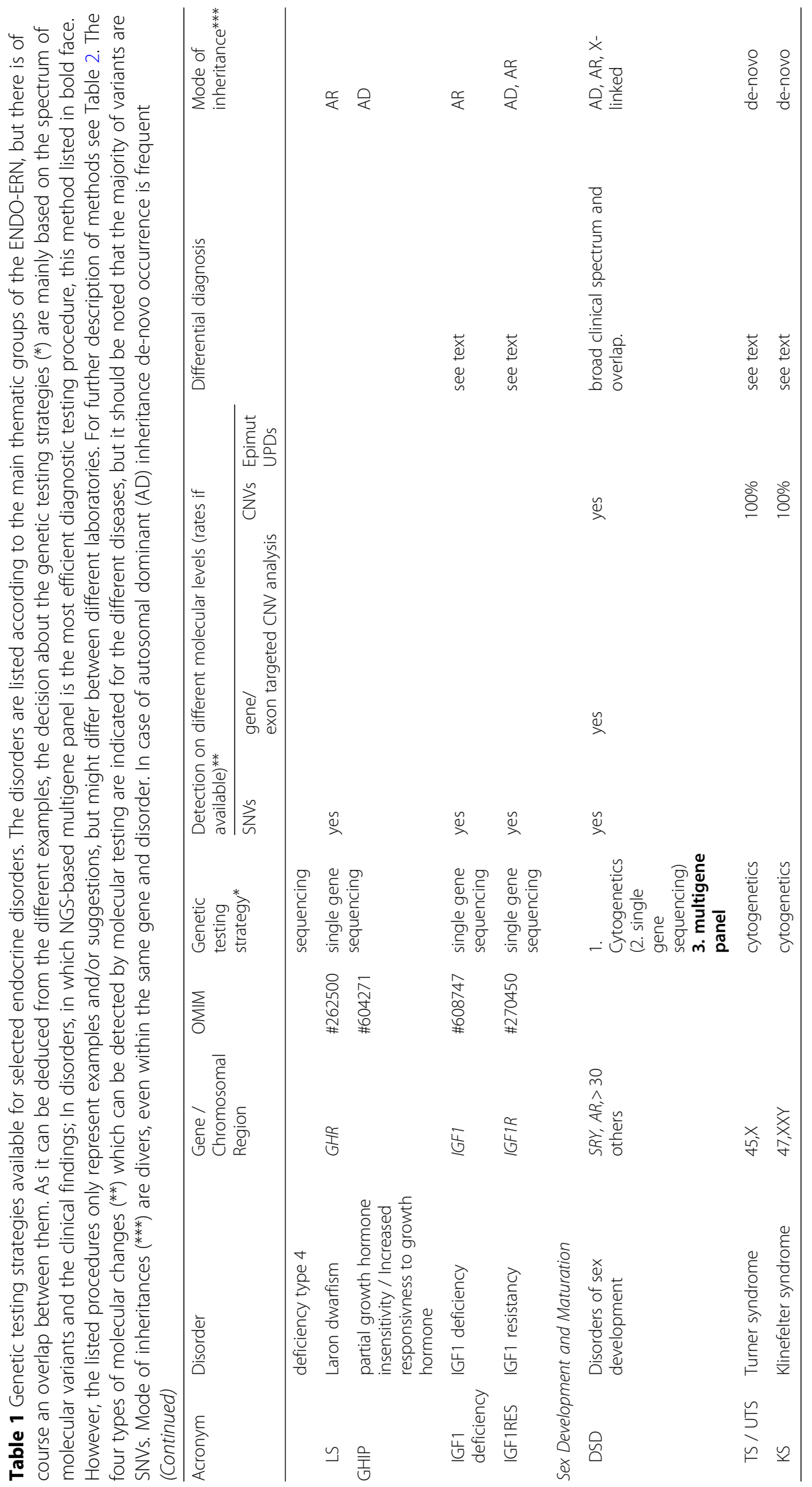


Clinical diagnosis:

Interdisciplinary evaluation: endocrine parameters, family history, imaging....

Pre-test counseling, information, informed consent

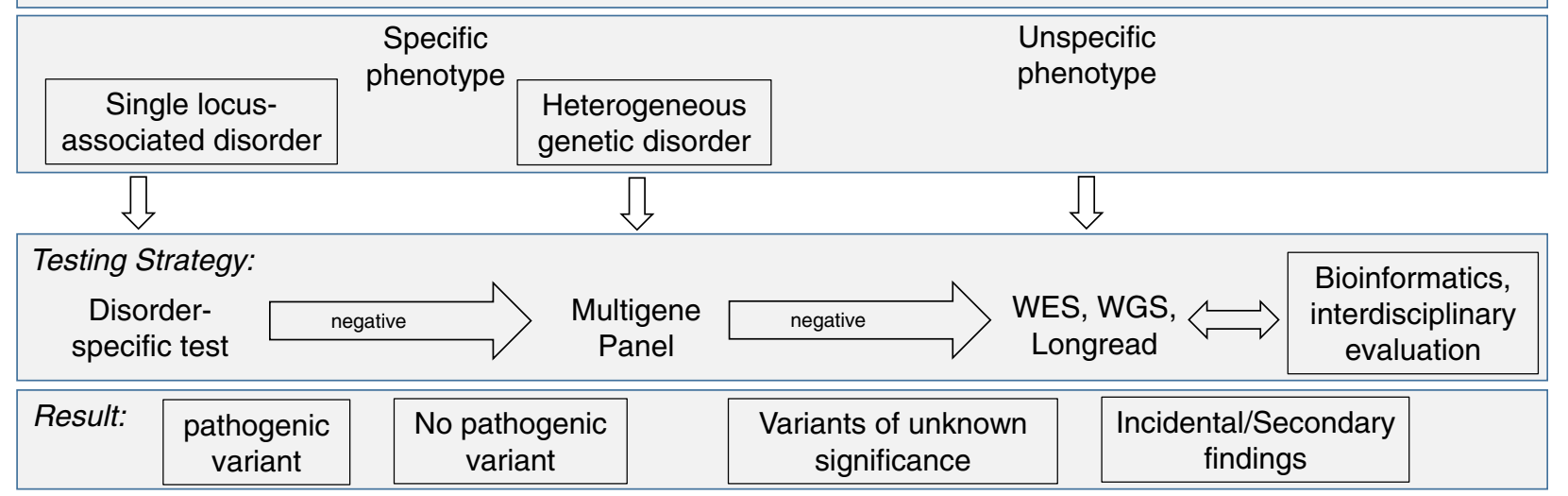

Post Test Counseling:

Disorder/variant specific intervention; Counseling and testing of family members

Fig. 1 Molecular diagnostic workup in endocrine diseases. Genetic testing should be based on a comprehensive clinical diagnostic workup as a detailed phenotypic description both of clinical as well as endocrine laboratory features is key to the accuracy and yield of molecular testing. If possible, a targeted testing strategy should be preferred to avoid incidental findings. However, for very heterogeneous disorders WES-based approaches are suitable (for examples see Table 1)

The central role of the precise molecular diagnosis as a decision aid for personalized clinical managements has meanwhile been shown for a broad range of endocrine disorders (Table 1), ranging from tumor predisposition syndromes $[10]$ to disorders characterized by growth defects [9], glucose and insulin homeostasis (for review: [11]), obesity and lipodystrophy, hypogonadotropic hypogonadism [12], disorders of skeletal metabolism [13], and disorders of sexual development [14].

The therapeutic relevance of a precise genetic diagnosis can be illustrated for patients with growth disturbance disorders associated with molecular defects affecting the chromosomal region 11p15.5, i.e. SilverRussell and Beckwith-Wiedemann syndrome (SRS, BWS). SRS is characterized by severe intrauterine and postnatal growth retardation, body asymmetry, feeding difficulties, relative macrocephaly at birth and characteristic facial features (for review: [15]). Among these features growth retardation is in the focus of the clinical management, and therapy is mainly based on recombinant growth hormone (rGH) treatment. The clinical heterogeneity results in an overlap with several other congenital growth retardation disorders and clinical misdiagnosis. These differential diagnoses comprise several tumor predisposition disorders (e.g. Bloom syndrome (OMIM \#210900) or Mulibrey nanism (OMIM \#253250)), for which rGH treatment is contraindicated [16]. In summary, the precise determination of the molecular cause of growth retardation in patients with SRS features is already nowadays required as the basis of a personalized therapeutic intervention (e.g. rGH treatment, tumor risk assessment). BWS is another example of an imprinting disorder associated with a broad spectrum of molecular alterations in 11p15.5. However, in contrast to SRS, BWS is characterized by overgrowth and an increased risk for embryonal tumors (for review: [17]). In fact, an association between specific molecular subtypes and tumor predisposition has been identified, and therefore the precise diagnosis of the molecular change in 11p15.5 has an impact on the tumor screening monitoring program [18]. Another example for the value of precise genetic subtyping for clinical decision-making is congenital hyperinsulinism due to $\mathrm{K}_{\mathrm{ATP}}$ channel mutations, where biallellic mutations in either $A B C C 8$ or KCNJ11 predict a diffuse type, while a single paternally inherited recessive mutation is highly suggestive of a focal type and may entail specific imaging and curative treatment (e.g. [11]).

Medical history should be accomplished by documentation of the family history of at least three generations and - if applicable - consanguinity and ethnicity. The family history might help to delineate the mode of inheritance and therefore provide hints at the disease-causing gene and mutation. However, the clinical manifestation and penetrance of genetic diseases can be highly variable even within the same family, therefore even minor 
clinical symptoms in apparently unaffected family members should also be checked thoroughly. Furthermore, there is a growing number of inherited disorders that do not exhibit the classical modes of inheritance, i.e. autosomal dominant, autosomal recessive or gonosomal inheritance ("Mendelian disorders"), but which differ from these rules. Mitochondrial inheritance is one example, as the respective disorders follow and exclusively maternal transmission pattern. Other examples of non-Mendelian inheritance are imprinting disorders like the PraderWilli and Silver-Russell syndromes, in which the sex of the parent transmitting the molecular basic mechanism contributes to the phenotypic expression (for review: $[19,20])$, as well as some trinucleotide disorders like the FMR1-associated premature ovarian failure and fragile $\mathrm{X}$ syndrome [21].

\section{Molecular alterations in endocrine disorders}

Though the majority of pathogenic variants consist of pathogenic variants affecting only single nucleotides (single nucleotide variants, SNVs), there are further types of molecular alterations which can be associated with endocrine disorders (Table 1). SNVs as well as losses, gains or rearrangements (e.g. deletions, duplications, insertion-deletions / indel) of a small number of basepairs commonly have an impact only on a single gene, whereas larger copy number variants (CNVs) might have an effect on several genes. In addition to alterations of the DNA itself, modification of imprinted gene clusters can be altered. These epimutations can result in the disturbance of the fine-tuned monoallelic expression of imprinted genes which are expressed either from the maternal or the paternal gene copy.

In the majority of known inherited endocrine disorders, the variant is either inherited and follows a classical Mendelian trait (i.e. autosomal-recessive, autosomaldominant, X-linked) or arises de-novo (in case of autosomal-dominant mutations). However, in the latter case these variants as well as epimutations might arise after fertilization, and can therefore occur as somatic mosaicism, meaning that not all cells of an organism carry the variant. In case of mosaicism, the ratio of cells with different (epi)genotypes can differ considerably, as demonstrated for Silver-Russell syndrome and McCune Albright syndrome (e.g. [22, 23])(Table 1). In some disorders, mosaicism is a well-known observation with a significant impact upon clinical manifestation and transmission risk (e.g. Neurofibromatosis type 1 [24]). As the presence of mosaicism can definitely not be excluded, testing of different tissues might be considered for every negative genetic test or particularly if an appropriate genetic test for a distinct phenotype comes back negative. Thus, the possibility of an undetected mosaicism should be discussed in a molecular genetic report if appropriate.

\section{Genetic tests and their applications in endocrine disorders}

Until recently, the detection of genomic variants of different sizes and nature often required the application of a step-wise process due to the limitations of the tests, accordingly this procedure was expensive and timeconsuming. The parallel analysis of several genes, or even the comprehensive analysis of the whole genome by NGS, is a quantum jump in routine molecular diagnostics. In heterogeneous disorders with hundreds of genes known to cause similar and overlapping phenotypes (Table 1), these factors can now be analyzed within the same diagnostic run and assessment pipeline. Additionally, in case of NGS formats addressing the whole exome or the whole genome (WES: whole exome sequencing; WGS: whole genome sequencing), new genetic causes of diseases can be identified. Thus, the capability of genomic NGS is enormous, but in a diagnostic context it should be applied after estimating the advantages and disadvantages (Table 2). In fact, the estimation of the pathogenicity of genomic variants obtained by both WES and WGS even in proteincoding genomic regions is a major challenge. As illustrated in Fig. 2 for a patient with an unspecific growth retardation phenotype, WES results in a huge number $(>50$, 000) of genomic variants. As WGS addresses hundredfold of base pairs as many as WES, the number of genomic variants grows exponentially, and accordingly their interpretation might be extremely laborious. Thus, the bioinformatic pipelines need to become further automated to facilitate the interpretation of data.

The decision on a genetic testing algorithm to confirm the clinical diagnosis of an endocrine disorder should consider both the range and types of pathogenic variants, as well as the appropriateness of the tests (Tables 1,2):

In endocrine disorders presenting with characteristic phenotypic expression and caused by pathogenic variants in only one gene, like multiple endocrine neoplasia type 1 (MEN1 gene) or von Hippel-Lindau syndrome ( $V H L$ gene), single gene testing is recommended. In some genetically heterogeneous disorders like BeckwithWiedemann syndrome and transient neonatal diabetes mellitus, a step-by-step molecular analysis might be meaningful, starting with the most frequent alterations. On the other hand, this stepwise strategy might not be useful in case of a suspected disorder with a genetically heterogenous background, variable expression and/or incomplete penetrance like permanent neonatal diabetes mellitus or hypothyroidism (for review: [25]). However, the causative genetic factors of several endocrine disorders can not be identified by these approaches, in these patients the application of WES and/or WGS should be 
Table 2 Currently applied methods in human genetic diagnostics of endocrine disorders: Applications, advantages and limitations. The methods can roughly be discriminated in respect to main type of molecular alteration they address, though some of them can also identify other changes. (*The currently used conventional diagnostic often address either copy number variants (CNVs, i.e. deletions and duplications) or single nucleotide variants (SNVs). In fact, CNVs represent a mutational burden in several genetic disorders. Therefore, parallel CNV assessment using alternate supplemental methods is normally required. For their identification, (semi)quantitative assays have been developed, and in human genetic testing multiplex ligation-dependent probe amplification (MLPA) is a broadly implemented diagnostic tool. However, the development of bioinformatics CNV pipelines for NGS data is in progress (e.g. [7]), and CNV detection by NGS is already in establishment. (*Multigene panels can either be based on targeted enrichment assays by which only the regions of interest are enriched in the wetlab, or they can be defined as a virtual WES dataset which has been filtered and analysed for the region of interest only. FISH: fluorescence in-situ hybridization, ASO: allele-specific oligonucleotide, MLPA: multiplex ligation-dependent probe amplification, SNP: single nucleotide polymorphism, CGH: comparative genome hybridization; WES: whole exome sequencing; WGS: whole genome sequencing; TGS: third generation sequencing; VUS: variant of unknown significance)

\begin{tabular}{|c|c|c|c|}
\hline Method/Panel & Target region & Chances / Advantages & Limitations / Disadvantages \\
\hline \multicolumn{4}{|c|}{ Methods mainly addressing CNVs } \\
\hline $\begin{array}{l}\text { Conventional } \\
\text { cytogenetics }\end{array}$ & Whole genome & $\begin{array}{l}\text { General overview on chromosomal } \\
\text { number and structure; Mosaicism might } \\
\text { be detected. }\end{array}$ & $\begin{array}{l}\text { Resolution is > } 5 \mathrm{Mb} \text {, smaller CNVs } \\
\text { escape detection. SNVs not detectable. } \\
\text { Cell culture required. Time and work } \\
\text { consuming. }\end{array}$ \\
\hline FISH & $\begin{array}{l}\text { Specific chromosomal regions, } \\
\text { whole chromosomes }\end{array}$ & $\begin{array}{l}\text { Identification of structural } \\
\text { rearragements. Detection of mosaicism. }\end{array}$ & $\begin{array}{l}\text { Target region has to be known or } \\
\text { should be suspected. Low resolution. } \\
\text { Intact cells required. }\end{array}$ \\
\hline
\end{tabular}
$\begin{array}{ll}\text { Multiplex Ligation- } & \text { Single gene testing; specific } \\ \text { dependent Probe Ampli- } & \text { genomic regions (60-100 bp) }\end{array}$ fication (MLPA)

Whole genome imaging Whole genome, specific chromosomal regions

Microarray (SNP array, Whole genome array $(\mathrm{CG})$

NGS assays (Panels, WES, See below WGS, TGS)

\section{Methods/Panels mainly addressing SNVs}

Single variant testing / Hotspot-mutation: e.g.

ASO, single fragment se-

SNVs, Trinucleotide repeat

quencing, fragment

analysis

Single gene testing (e.g. Single genes

Sanger sequencing)

Multigene panel*

Genomic sequences (mainly coding regions and neighbored intronic regions) of selected genes associated with specific phenotypes

Clinical exome

Coding and regulatory domains of all genes known to harbor clinically relevant variants

Whole Exome sequencing/WES
Coding regions of $\sim 19,000$ protein coding genes ( 180,000 exons); $1-$
Specific detection of genomic CNVs, appropriate for identification of deletions/duplications of selected exons.

General overview on chromosomal number and structure; Identification of structural rearrangements.

General overview on copy number variants, resolution of few kilobases.

Comprehensive overview, dependent on the bioinformatics pipeline CNVs and structural variants can be detected

Very specific, fast, cheap.

Target specific, appropriate and economic tool for monogenetic single locus disorders with characteristic clinical signs.

Target analyses of a group of genes associated with specific phenotypes. Low chance for incidental findings.

Suitable for heterogeneous disorders with specific clinical features.

Analysis of a huge number of clinically relevant genes. Both disease-specific genes as well as differential diagnostic genes are analyzed. Suitable for disorders with unspecific clinical features

All protein coding regions are covered. Identification of new disease-causing
Only targeted fragments are quantified. Restricted number of fragments per analysis (up to 60).

Detection of both numerical and structural aberrations with a relative high resolution $(>150 \mathrm{~kb})$. Fresh samples required.

Balanced chromosomal aberrations not detectable. Resolution on single gene level might be difficult.

see below

Only single variants or trinucleotide repeats are addressed.

Large genes difficult to analyze. Not appropriate for heterogeneous disorders.

In case new genes are identified, adaption of a panel might be difficult or delayed in time. Variants in genes associated with overlapping phenotypes (differential diagnoses) might not be included in a panel. Non-coding regions are not covered.

Increased probability to detect incidental findings. Increased probability for VUS. Fixed panel, new diseaseassociated genes are integrated after a delay. Non-coding regions are not covered.

Detection of VUS and incidental findings probable. Non-coding regions are not 
Table 2 Currently applied methods in human genetic diagnostics of endocrine disorders: Applications, advantages and limitations. The methods can roughly be discriminated in respect to main type of molecular alteration they address, though some of them can also identify other changes. (*The currently used conventional diagnostic often address either copy number variants (CNVs, i.e. deletions and duplications) or single nucleotide variants (SNVs). In fact, CNVs represent a mutational burden in several genetic disorders. Therefore, parallel CNV assessment using alternate supplemental methods is normally required. For their identification, (semi)quantitative assays have been developed, and in human genetic testing multiplex ligation-dependent probe amplification (MLPA) is a broadly implemented diagnostic tool. However, the development of bioinformatics CNV pipelines for NGS data is in progress (e.g. [7]), and CNV detection by NGS is already in establishment. (*Multigene panels can either be based on targeted enrichment assays by which only the regions of interest are enriched in the wetlab, or they can be defined as a virtual WES dataset which has been filtered and analysed for the region of interest only. FISH: fluorescence in-situ hybridization, ASO: allele-specific oligonucleotide, MLPA: multiplex ligation-dependent probe amplification, SNP: single nucleotide polymorphism, CGH: comparative genome hybridization; WES: whole exome sequencing; WGS: whole genome sequencing; TGS: third generation sequencing; VUS: variant of unknown significance) (Continued)

\begin{tabular}{|c|c|c|c|}
\hline Method/Panel & Target region & Chances / Advantages & Limitations / Disadvantages \\
\hline & $2 \%$ of the human genome & $\begin{array}{l}\text { genes possible. Suitable for disorders } \\
\text { with unspecific phenotypes }\end{array}$ & $\begin{array}{l}\text { covered. Analysis, interpretation and } \\
\text { storage of large datasets required. }\end{array}$ \\
\hline $\begin{array}{l}\text { Whole Genome } \\
\text { sequencing/WGS (short } \\
\text { read) }\end{array}$ & Total human genome & $\begin{array}{l}\text { Whole genome is analyzed. } \\
\text { New genes as well as genomic variants } \\
\text { in non-coding regions can be identi- } \\
\text { fied. Suitable for disorders with unspe- } \\
\text { cific phenotypes. }\end{array}$ & $\begin{array}{l}\text { Detection of VUS and incidental findings } \\
\text { very probable. Analysis, interpretation } \\
\text { and storage of very large datasets } \\
\text { required. }\end{array}$ \\
\hline $\begin{array}{l}\text { Third Generation } \\
\text { Sequencing (long read, } \\
\text { TGS) }\end{array}$ & $\begin{array}{l}\text { Ranging from defined } \\
\text { chromosomal region to whole } \\
\text { genome }\end{array}$ & $\begin{array}{l}\text { Identification of chromosomal } \\
\text { rearrangements and CNVs. } \\
\text { Determination of physical breakpoints. }\end{array}$ & $\begin{array}{l}\text { Resolution on single nucleotide level } \\
\text { currently difficult. }\end{array}$ \\
\hline \multicolumn{4}{|l|}{ Methylation-specific testing } \\
\hline $\begin{array}{l}\text { Single testing of } \\
\text { imprinted loci (MS } \\
\text { MLPA, MS } \\
\text { pyrosequencing) }\end{array}$ & $\begin{array}{l}\text { Single differentially methylated } \\
\text { regions }\end{array}$ & $\begin{array}{l}\text { Target specific, appropriate and } \\
\text { economic tool for specific imprinting } \\
\text { disorders. }\end{array}$ & $\begin{array}{l}\text { Not appropriate for heterogeneous } \\
\text { phenotypes. Multilocus disturbances are } \\
\text { not detected. }\end{array}$ \\
\hline $\begin{array}{l}\text { Methylation-specific } \\
\text { tests/Methylome }\end{array}$ & $\begin{array}{l}\text { Ranging from single CpGs (e.g. PCR) } \\
\text { and multilocus tests (e.g. MLPA) to } \\
\text { genomewide analyses (array, NGS) }\end{array}$ & $\begin{array}{l}\text { Identification of imbalanced } \\
\text { methylation at selected CpGs. } \\
\text { Different causes aberrant methylation } \\
\text { pattern can be identified (UPD, CNV, } \\
\text { epimutation). New and/or rare entities } \\
\text { associated with disturbed imprinting } \\
\text { can be identified. }\end{array}$ & $\begin{array}{l}\text { Dependent on the test, different causes } \\
\text { of aberrant methylation cannot be } \\
\text { discriminated. In case of single and } \\
\text { multilocus analyses non-targeted loci es- } \\
\text { cape detection. In case of genome-wide } \\
\text { analyses large datasets require compre- } \\
\text { hensive analyses and control data. }\end{array}$ \\
\hline $\begin{array}{l}\text { NGS assays: Panels, WES, } \\
\text { WGS, TGS }\end{array}$ & See above & $\begin{array}{l}\text { Comprehensive overview on altered } \\
\text { methylation patterns. }\end{array}$ & See above \\
\hline \multicolumn{4}{|l|}{ Transcriptome } \\
\hline Transcriptome & $\begin{array}{l}\text { Set of all RNA molecules in one cell } \\
\text { or a population of cells }\end{array}$ & $\begin{array}{l}\text { Identification of variants affecting } \\
\text { splicing and causing allelic imbalances. } \\
\text { Enhancement of the efficiency to } \\
\text { identify functionally relevant variants. } \\
\text { Complementary tool for WES and WGS. }\end{array}$ & $\begin{array}{l}\text { Detected RNAs depend on the used } \\
\text { tissues/cells. } \\
\text { RNAs which are not expressed in this } \\
\text { tissue are missed. Integration with data } \\
\text { from other omic assays required }\end{array}$ \\
\hline
\end{tabular}

considered. In fact, the deciphering of a disease-causing genetic change in these patients can be more successful if samples from the parents are also included in the analysis (trio-analysis).

In summary, specific tests targeting variants and genes will also be applied in the future in disorders with a small spectrum of mutations testing of which provides a high detection yield, whereas NGS based assays are used in genetically heterogeneous entities.

\section{Technical aspects of genetic testing in the NGS era} The chosen assay also influences the source and amount of the patients' sample. For conventional cytogenetics, viable cells are required, whereas most molecular tests, including NGS, are based on genomic DNA which can be principally isolated from all freshly drawn or archived tissues. However, the molecular strategies also differ in the need of DNA.

The use of NGS gene panels allows to select and target specific groups of genes, and for some disorders it is therefore the first choice of testing. In contrast, NGSbased approaches covering hundreds of unselected genes or even the whole genome might lead to the inclusion of factors in the diagnostic setting that are functional candidates. The huge number of variants obtained by exome or genome-wide approaches reflect the variability and 


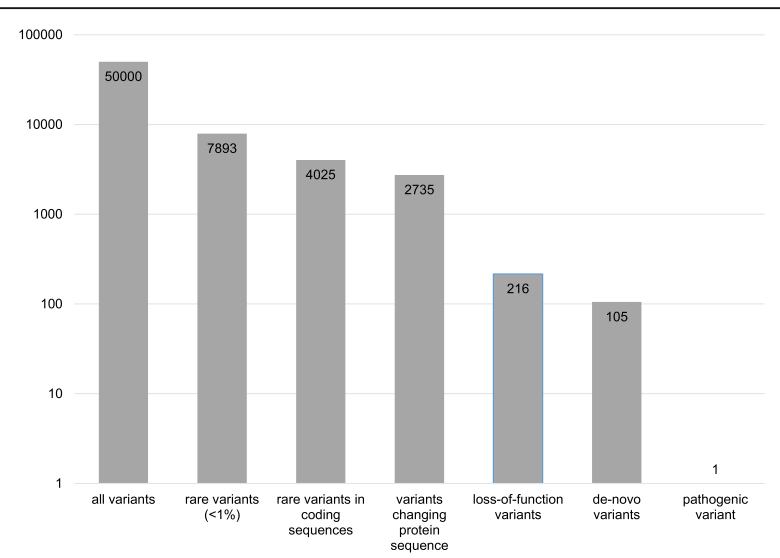

Fig. 2 Example of filtering of genomic variants obtained by whole exome sequencing to identify a pathogenic variant in a growth retarded patientn. By applying different filter parameters like variant frequencies, pathogenicity and mode of inheritance, the number of genomic variants can be reduced and the disease-causing variant can be identified (numbers of variants are shown on the $y$ axis)

complexity of the human genome. In fact, the majority of variants represent non-pathogenic polymorphisms which also occur in control cohorts (Fig. 2). Thus, the key for a successful and efficient NGS data analysis is the stringent filtering by bioinformatic pipelines which commonly refer to (a) databases of genetic variants in humans, (b) pathogenicity prediction tools, and (c) different modes of genetic inheritance.

a) With the increase of biological data ascertained by high-throughput omics technologies, the demand of databases on biological information has increased and the number of repositories is permanently growing (Nucleic Acids Research references 180 databases [26]). These curated databases daily exchange and update new data based on raw data from high-throughput laboratories.

b) The freely or commercially available in-silico tools to predict the pathogenicity of a genomic variant mainly rely on its biochemical, structural, and functional properties, and its evolutionary conservation across species. Recent studies that compared the performance of the major prediction tools applied in genetic diagnostic testing have revealed a diverse picture of their reliability (for review: [27]). Therefore, the determination of pathogenicity should also consider additional information including variant frequencies obtainable from databases (see (a)), and segregation analyses in a family (see (c)), and - if possible - functional analysis.

c) Segregation analysis seeking for the association of a genetic variant with the phenotype in a family is an appropriate tool to corroborate its pathogenicity.
The combination of these information should support the laboratory to delineate the pathogenicity of a genomic variant. With the guidelines for interpretation of genomic variants suggested by the American College of Medical Genetics [28], a widely accepted system for variant classification has been developed (Table 3). Whereas the classification of a variant as benign/likely benign or pathogenic/likely pathogenic either excludes or confirms its pathogenicity, the prediction of a considerable number of variants remains ambiguous (so-called variants of unknown significance - VUS). With the application of WES or WGS, the number of detectable variants including VUS grows exponentially, and NGS data therefore requires a stringent variant filtering (Fig. 2). These aspects should clearly be addressed before the application of such a broad test to avoid misunderstandings and unrealistic expectations, and the patients and their families should be informed about these scenarios with the help of appropriate patient counseling, information and informed consent forms [29]. However, the physician should be aware of the slight possibility that genomic variants which are classified as pathogenic/likely pathogenic at the time of diagnosis might be downgraded to benign later due to an increase of knowledge and datasets.

Another challenge in the diagnostic use of WES/WGS is the handling of incidental findings, i.e. genetic alterations associated with conditions or diseases unrelated to the patient's present condition for which current tests are being performed but with important clinical ramifications. To circumvent these putative outcomes, which are difficult to manage in routine diagnostic workup and counseling, to reduce the costs for consumables and to avoid excessive amounts of data, targeted NGS panels have been established as an appropriate tool for NGS-based genetic testing (Table 1). However, multigene panels are not suitable for analysis of patients with unspecific phenotypes. In this situation the use of so-called "clinical exomes" might be discussed which target protein-coding regions of all genes for which disease-causing variants have been reported (e.g. "Kingsmore panel"). In fact, not all advantages and disadvantages of the different assay formats can be addressed in this paper, and every month new improvements of wet-lab and bioinformatic NGS tools as well as functional assays and suitable models to further characterize new variants are being published. For unusual phenotypes and challenging diagnostic scenarios, it is therefore recommended to contact laboratories experienced in NGS analysis in time for the up-to-date NGS testing strategies in connection with the pathology to be explored.

Laboratories offering genetic tests should implement a quality management system [30]. It should follow the 
Table 3 Classification of genetic variants in routine diagnostics, leaned on the criteria suggested by the American College of Medical Genetics [28]

\begin{tabular}{lll}
\hline $\begin{array}{l}\text { Clinical } \\
\text { significance }\end{array}$ & Pathogenicity classes & Major Criteria \\
\hline $\begin{array}{ll}\text { Clinical } \\
\text { significance }\end{array}$ & $\begin{array}{l}\text { Pathogenic } \\
\text { Likely pathogenic }\end{array}$ & $\begin{array}{l}\text { - The variant affects the structure and function of the gene/protein. } \\
\text { - The variant affects a gene in which similar variants are known to be disease-causing. } \\
\end{array}$ \\
& $\begin{array}{l}\text { - The pathogenic nature of the variant is supported by epidemiological data, bioinformatic } \\
\text { prediction and segregation analyses. }\end{array}$ \\
Uncertain & Variant of unknown & - Not all parameters of pathogenicity are fulfilled. \\
significance & significance (VUS) & - Bioinformatics prediction of pathogenicity but without final confirmation. \\
No clinical & Likely benign & - Epidemiological and bioinformatics data indicate that the variant is not pathogenic. \\
significance & Benign & - These variants are commonly not reported but might be available on request.
\end{tabular}

national rules, but it should be leaned on the latest version of the ISO15189 standard, which specifies requirements for quality and competence in medical laboratories. Participation in external quality assessment schemes is a further key element of quality assurance in molecular genetic diagnostics, and these schemes help to test the laboratory workflow as well as the proficiency of data interpretation and reporting.

With the publication of guidelines for NGS testing, the European Society of Human Genetics has undertaken an essential step towards an international standard of NGSbased diagnostics [31].

\section{Conclusions}

The implementation of NGS assays in DNA testing has significantly increased its diagnostic yield [4, 32], but it still leaves a considerable number of patients with an unusual clinical phenotype without molecular confirmation. With the rapid development of wet-lab assays and bioinformatic NGS pipelines it can be expected that the increasing application of NGS, as well as the improvements of databases and software tools underlying its data interpretation will significantly increase the rate of cases with a solved molecular basis. By complementing genomic NGS data with transcriptome (RNAseq) as well as methylome data and information from multiple omic sources, future diagnostic approaches will additionally become more comprehensive [33].

The growing knowledge on the contribution of genetic factors to endocrine disorders and the rapid implementation of new molecular tools in the diagnostic settings makes the interpretation of diagnostic data increasingly complex. Therefore, the data assessment should be embedded in interdisciplinary discussions using all available clinical and molecular information. Therefore, the metabolic and hormonal assessment remain fundamental. However, WES, WGS and further NGS formats are indispensable tools to identify new pathophysiological mechanisms of human disorders and to improve diagnostic algorithms. In the future, nearly all genetic alterations will be addressable by comprehensive NGS approaches.
Finally, the knowledge on the genetic cause of a disease does not only allow a precise clinical management, but it also helps to avoid invasive and expensive diagnostic tests which burden the patient, and lead to a faster diagnosis allowing an earlier and therefore more effective medical intervention (for review: [25]). The early diagnosis of a genetically based disorder supports the patients and their family in their self-determined planning of life as early as possible. Furthermore, it allows an accurate prognosis of recurrence risks for family planning as the basis of genetic counselling. Asymptomatic carriers of pathogenic variants can be identified, and prenatal testing might be offered, where appropriate.

\section{Abbreviations \\ AMH: Anti-Müllerian hormone; BWS: Beckwith-Wiedemann syndrome CNV: Copy Number Variant; ENDO-ERN: European Reference Network on Rare Endocrine Conditions; HPO: Human Phenotype Ontology; PMDS: Persistent Müllerian Duct Syndrome; SNV: Single Nucleotide Variant; SRS: Silver-Russell syndrome; VUS: Variant of Unknown Significance; WES: Whole Exome Sequencing; WGS: Whole Genome Sequencing}

\section{Acknowledgements}

We thank all ENDO-ERN partners for stimulating discussions on genetic testing in endocrine disorders.

\section{Weblinks}

CPMS: https://cpms.ern-net.eu/login/

EMBL: https://www.embl.de/

Endo-ERN: https://endo-ern.eu/

Genecards: https://www.nature.com/ejhg/articles?type=clinical-utility-genecard

HPO: https://hpo.jax.org/app/

NCBI: https://www.ncbi.nlm.nih.gov/

Orphanet: https://www.orpha.net/consor/cgi-bin/Disease_Search.php?lng=EN

\section{Authors' contributions}

TE, ME and IK have drafted the paper. AJ, THJ, IN, GM, GJ, AMP and $\mathrm{OH}$ have contributed endocrinological aspects to the content, according to their field of expertise. MZ and DP have added their knowledge on genetic basis and diagnostics. $\mathrm{OH}$ and AMP have supervised the writing. All authors and the ENDO-ERN members (see list) have approved the paper.

\section{Funding}

The authors are members of the European Reference Network on Rare Endocrine Conditions (https://endo-ern.eu/). Endo-ERN is a European Reference Network co-funded by the European Union's 3rd Health Programme (CHAFEA FPA grant No 739527).TE is supported by the Deutsche Forschungsgemeinschaft (DFG, EG110/15-1). 


\section{Availability of data and materials}

Not applicable.

\section{Ethics approval and consent to participate}

Not applicable.

\section{Consent for publication \\ Not applicable.}

\section{Competing interests}

The authors declare that they have no competing interests.

\section{Author details}

'Institute of Human Genetics, Medical Faculty, RWTH Aachen, Pauwelsstr. 30, 52074 Aachen, Germany. ${ }^{2}$ Department of Growth and Reproduction, Rigshospitalet, University Hospital of Copenhagen, Copenhagen, Denmark. ${ }^{3}$ International Center for Research and Research Training in Endocrine Disruption of Male Reproduction and Child Health (EDMaRC), Rigshospitalet, University of Copenhagen, Copenhagen, Denmark. ${ }^{4}$ INSERM, Centre de Recherche Saint-Antoine, Sorbonne Université, UFR Médecine, AP-HP, Hôpital Armand Trousseau-Explorations Fonctionnelles Endocriniennes, Paris, France. ${ }^{5}$ Unit of Endocrinology, Diabetes Mellitus and Metabolism, ARETAIEION Hospital, Faculty of Medicine, National and Kapodistrian University of Athens, Athens, Greece. ${ }^{6}$ Department of Internal Medicine and Clinical Nutrition, Institute of Medicine, Sahlgrenska Academy, University of Gothenburg and Department of Endocrinology at Sahlgrenska University Hospital,

Gothenburg, Sweden. ' $5 e c t i o n$ of Endocrine Surgery, Department of General, Visceral and Transplantation Surgery, Johannes Gutenberg University Medical Center, Mainz, Germany. ${ }^{8}$ Institute of Human Genetics,

Otto-von-Guericke-Universität Magdeburg, Magdeburg, Germany. ${ }^{9}$ Center for Pediatrics and Adolescent Medicine, Johannes Gutenberg University Medical Center, Mainz, Germany. ${ }^{10}$ Department of Medicine, Division of Endocrinology, Leiden University Medical Center, Leiden, the Netherlands. ${ }^{11}$ Department of Paediatrics and Adolescent Medicine, Division of Paediatric Endocrinology and Diabetes, University of Lübeck, Lübeck, Germany.

\section{Received: 6 March 2020 Accepted: 25 May 2020}

Published online: 08 June 2020

\section{References}

1. Baird PA, Anderson TW, Newcombe HB, Lowry RB. Genetic disorders in children and young adults: a population study. Am J Hum Genet. 1988; 42(5):677-93.

2. Chong JX, Buckingham KJ, Jhangiani SN, Boehm C, Sobreira N, Smith JD, Harrell TM, MJ MM, Wiszniewski W, Gambin T, Coban Akdemir ZH, Doheny K, Scott AF, Avramopoulos D, Chakravarti A, Hoover-Fong J, Mathews D, Witmer PD, Ling H, Hetrick K, Watkins L, Patterson KE, Reinier F, Blue E, Muzny D, Kircher M, Bilguvar K, Lopez-Giraldez F, Sutton VR, Tabor HK, Leal SM, Gunel M, Mane S, Gibbs RA, Boerwinkle E, Hamosh A, Shendure J, Lupski JR, Lifton RP, Valle D, Nickerson DA, Centers for Mendelian G, Bamshad MJ. The genetic basis of mendelian phenotypes: discoveries, challenges, and opportunities. Am J Hum Genet. 2015;97(2):199-215.

3. Shendure J, Balasubramanian S, Church GM, Gilbert W, Rogers J, Schloss JA, Waterston RH. DNA sequencing at 40: past, present and future. Nature. 2017:550(7676):345-53.

4. Cordoba M, Rodriguez-Quiroga SA, Vega PA, Salinas V, Perez-Maturo J, Amartino H, Vasquez-Dusefante C, Medina N, Gonzalez-Moron D, Kauffman MA. Whole exome sequencing in neurogenetic odysseys: an effective, costand time-saving diagnostic approach. PLoS One. 2018;13(2):e0191228.

5. Forlenza GP, Calhoun A, Beckman KB, Halvorsen T, Hamdoun E, Zierhut H, Sarafoglou K, Polgreen LE, Miller BS, Nathan B, Petryk A. Next generation sequencing in endocrine practice. Mol Genet Metab. 2015;115(2-3):61-71.

6. Kamps R, Brandao RD, Bosch BJ, Paulussen AD, Xanthoulea S, Blok MJ, Romano A. Next-generation sequencing in oncology: genetic diagnosis, risk prediction and cancer classification. Int J Mol Sci. 2017;18(2):308.

7. Kerkhof J, Schenkel LC, Reilly J, McRobbie S, Aref-Eshghi E, Stuart A, Rupar CA Adams P, Hegele RA, Lin H, Rodenhiser D, Knoll J, Ainsworth PJ, Sadikovic B. Clinical validation of copy number variant detection from targeted nextgeneration sequencing panels. J Mol Diagn. 2017;19(6):905-20.
8. Doehnert U, Bertelloni S, Werner R, Dati E, Hiort O. Characteristic features of reproductive hormone profiles in late adolescent and adult females with complete androgen insensitivity syndrome. Sex Dev. 2015;9(2):69-74.

9. Seaver LH, Irons M, American College of Medical Genetics Professional P, Guidelines C. ACMG practice guideline: genetic evaluation of short stature. Genet Med. 2009;11(6):465-70.

10. Goudie C, Hannah-Shmouni F, Kavak M, Stratakis CA, Foulkes WD. 65 YEARS OF THE DOUBLE HELIX: endocrine tumour syndromes in children and adolescents. Endocr Relat Cancer. 2018;25(8):T221-T44.

11. Mohnike K, Wieland I, Barthlen W, Vogelgesang S, Empting S, Mohnike W, Meissner T, Zenker M. Clinical and genetic evaluation of patients with KATP channel mutations from the German registry for congenital hyperinsulinism. Horm Res Paediatr. 2014;81(3):156-68.

12. Boehm U, Bouloux PM, Dattani MT, de Roux N, Dode C, Dunkel L, Dwyer AA, Giacobini P, Hardelin JP, Juul A, Maghnie M, Pitteloud N, Prevot V, Raivio T, Tena-Sempere M, Quinton R, Young J. Expert consensus document: European consensus statement on congenital hypogonadotropic hypogonadism-pathogenesis, diagnosis and treatment. Nat Rev Endocrinol. 2015;11(9):547-64.

13. Masi L, Agnusdei D, Bilezikian J, Chappard D, Chapurlat R, Cianferotti L, Devolgelaer JP, El Maghraoui A, Ferrari S, Javaid MK, Kaufman JM, Liberman UA, Lyritis G, Miller P, Napoli N, Roldan E, Papapoulos S, Watts NB, Brandi ML. Taxonomy of rare genetic metabolic bone disorders. Osteoporos Int. 2015;26(10):2529-58.

14. Audi L, Ahmed SF, Krone N, Cools M, McElreavey K, Holterhus PM, Greenfield A, Bashamboo A, Hiort O, Wudy SA, McGowan R, The EUCA. Genetics in Endocrinology: approaches to molecular genetic diagnosis in the management of differences/disorders of sex development (DSD): position paper of EU COST action BM 1303 'DSDnet'. Eur J Endocrinol. 2018; 179(4):R197-206.

15. Wakeling EL, Brioude F, Lokulo-Sodipe O, O'Connell SM, Salem J, Bliek J, Canton AP, Chrzanowska KH, Davies JH, Dias RP, Dubern B, Elbracht M, Giabicani E, Grimberg A, Gronskov K, Hokken-Koelega AC, Jorge AA, Kagami M, Linglart A, Maghnie M, Mohnike K, Monk D, Moore GE, Murray PG, Ogata T, Petit 1O, Russo S, Said E, Toumba M, Tumer Z, Binder G, Eggermann T, Harbison MD, Temple IK, Mackay DJ, Netchine I. Diagnosis and management of Silver-Russell syndrome: first international consensus statement. Nat Rev Endocrinol. 2017;13(2):105-24.

16. Meyer E, Lim D, Pasha S, Tee LJ, Rahman F, Yates JR, Woods CG, Reik W, Maher ER. Germline mutation in NLRP2 (NALP2) in a familial imprinting disorder (Beckwith-Wiedemann syndrome). PLoS Genet. 2009;5(3):e1000423.

17. Brioude F, Kalish JM, Mussa A, Foster AC, Bliek J, Ferrero GB, Boonen SE, Cole T, Baker R, Bertoletti M, Cocchi G, Coze C, De Pellegrin M, Hussain K, Ibrahim A, Kilby MD, Krajewska-Walasek M, Kratz CP, Ladusans EJ, Lapunzina P, Le Bouc Y, Maas SM, Macdonald F, Ounap K, Peruzzi L, Rossignol S, Russo S, Shipster C, Skorka A, Tatton-Brown K, Tenorio J, Tortora C, Gronskov K, Netchine I, Hennekam RC, Prawitt D, Tumer Z, Eggermann T, Mackay DJG, Riccio A, Maher ER. Expert consensus document: Clinical and molecular diagnosis, screening and management of Beckwith-Wiedemann syndrome: an international consensus statement. Nat Rev Endocrinol. 2018;14(4):229-49.

18. Mussa A, Molinatto C, Baldassarre G, Riberi E, Russo S, Larizza L, Riccio A, Ferrero GB. Cancer risk in Beckwith-Wiedemann syndrome: a systematic review and meta-analysis outlining a novel (Epi)genotype specific Histotype targeted screening protocol. J Pediatr. 2016;176:142-9 e1.

19. Soellner L, Begemann M, Mackay DJ, Gronskov K, Tumer Z, Maher ER, Temple IK, Monk D, Riccio A, Linglart A, Netchine I, Eggermann T. Recent advances in imprinting disorders. Clin Genet. 2017;91(1):3-13.

20. Valadares LP, Meireles CG, De Toledo IP, Santarem de Oliveira R, Goncalves de Castro LC, Abreu AP, Carroll RS, Latronico AC, Kaiser UB, Guerra ENS, Lofrano-Porto A. MKRN3 mutations in central precocious puberty: a systematic review and meta-analysis. J Endocr Soc. 2019;3(5):979-95.

21. Hoyos $L R$, Thakur M. Fragile $X$ premutation in women: recognizing the health challenges beyond primary ovarian insufficiency. J Assist Reprod Genet. 2017;34(3):315-23.

22. Azzi S, Rossignol S, Steunou V, Sas T, Thibaud N, Danton F, Le Jule M, Heinrichs C, Cabrol S, Gicquel C, Le Bouc Y, Netchine I. Multilocus methylation analysis in a large cohort of 11 p15-related foetal growth disorders (Russell silver and Beckwith Wiedemann syndromes) reveals simultaneous loss of methylation at paternal and maternal imprinted loci. Hum Mol Genet. 2009;18(24):4724-33.

23. Romanet P, Philibert P, Fina F, Cuny T, Roche C, Ouafik L, Paris F, Reynaud R, Barlier A. Using digital droplet polymerase chain reaction to detect the mosaic 
GNAS mutations in whole blood DNA or circulating cell-free DNA in fibrous dysplasia and McCune-Albright syndrome. J Pediatr. 2019;205:281-5 e4.

24. Messiaen L, Vogt J, Bengesser K, Fu C, Mikhail F, Serra E, Garcia-Linares C, Cooper DN, Lazaro C, Kehrer-Sawatzki H. Mosaic type-1 NF1 microdeletions as a cause of both generalized and segmental neurofibromatosis type-1 (NF1). Hum Mutat. 2011;32(2):213-9.

25. Persani L, Rurale G, de Filippis T, Galazzi E, Muzza M, Fugazzola L. Genetics and management of congenital hypothyroidism. Best Pract Res Clin Endocrinol Metab. 2018;32(4):387-96.

26. Rigden DJ, Fernandez XM. The 2018 nucleic acids research database issue and the online molecular biology database collection. Nucleic Acids Res. 2018;46(D1):D1-7.

27. Ernst C, Hahnen E, Engel C, Nothnagel M, Weber J, Schmutzler RK, Hauke J. Performance of in silico prediction tools for the classification of rare BRCA1/ 2 missense variants in clinical diagnostics. BMC Med Genet. 2018:11(1):35.

28. Richards S, Aziz N, Bale S, Bick D, Das S, Gastier-Foster J, Grody WW, Hegde M, Lyon E, Spector E, Voelkerding K, Rehm HL, Committee ALQA. Standards and guidelines for the interpretation of sequence variants: a joint consensus recommendation of the American College of Medical Genetics and Genomics and the Association for Molecular Pathology. Genet Med. 2015; 17(5):405-24.

29. Vears DF, Niemiec E, Howard HC, Borry P. Analysis of VUS reporting, variant reinterpretation and recontact policies in clinical genomic sequencing consent forms. Eur J Hum Genet. 2018;26(12):1743-51.

30. Berwouts S, Morris MA, Dequeker E. Approaches to quality management and accreditation in a genetic testing laboratory. Eur J Hum Genet. 2010; 18(Suppl 1):S1-19.

31. Matthiis G, Souche E, Alders M, Corveleyn A, Eck S, Feenstra I, Race V, Sistermans E, Sturm M, Weiss M, Yntema H, Bakker E, Scheffer H, Bauer P, EuroGentest, European Society of Human G. Guidelines for diagnostic nextgeneration sequencing. Eur J Hum Genet. 2016;24(1):2-5.

32. Wright $C F$, FitzPatrick DR, Firth HV. Paediatric genomics: diagnosing rare disease in children. Nat Rev Genet. 2018:19(5):325.

33. Fresard L, Smail C, Ferraro NM, Teran NA, Li X, Smith KS, Bonner D, Kernohan KD, Marwaha S, Zappala Z, Balliu B, Davis JR, Liu B, Prybol CJ, Kohler JN, Zastrow DB, Reuter CM, Fisk DG, Grove ME, Davidson JM, Hartley T, Joshi R, Strober BJ, Utiramerur S, Undiagnosed Diseases N, Care4Rare Canada C, Lind L, Ingelsson E, Battle A, Bejerano G, Bernstein JA, Ashley EA, Boycott KM, Merker JD, Wheeler MT, Montgomery SB. Identification of raredisease genes using blood transcriptome sequencing and large control cohorts. Nat Med. 2019;25(6):911-9.

\section{Publisher's Note}

Springer Nature remains neutral with regard to jurisdictional claims in published maps and institutional affiliations.

Ready to submit your research? Choose BMC and benefit from:

- fast, convenient online submission

- thorough peer review by experienced researchers in your field

- rapid publication on acceptance

- support for research data, including large and complex data types

- gold Open Access which fosters wider collaboration and increased citations

- maximum visibility for your research: over $100 \mathrm{M}$ website views per year

At $\mathrm{BMC}$, research is always in progress.

Learn more biomedcentral.com/submissions 